\title{
A Triangulation-Based MRI-Guided Method for TMS Coil Positioning
}

\author{
Jamila Andoh and Jean-Luc Martinot \\ ${ }^{1}$ Montreal Neurological Institute, McGill University \\ 2International Laboratory for Brain, Music, and Sound (BRAMS), Montreal \\ 3INSERM- CEA Research Unit 1000 "Neuroimaging \& Psychiatry"; Univ Paris-Sud, and \\ Univ. Paris Descartes; SHFJ, and Maison de Solenn - Cochin Hospital; Orsay - Paris \\ 1,2Canada \\ ${ }^{3}$ France
}

\section{Introduction}

\subsection{From lesions to functional neuroimaging}

The first model about the cerebral organization of cognitive functions was based on lesion observation. This consisted in inferring association between a particular deficit of the language (e.g., word production) and a brain lesion observed post-mortem (Wernicke, 1874; Broca, 1861). Brain imaging techniques (e.g., functional Magnetic Resonance Imaging) provide complementary but different types of information regarding brain-behavior relationships. By providing indirect measures of cerebral activity such as blood flow or oxygen consumption, neuroimaging techniques enable one to establish a relationship between the activities of different brain areas and the cognitive processes being performed (Bestmann et al. 2003; Frith 1997). For instance, the combination of functional magnetic resonance imaging (fMRI) with language tasks has shown that language-related areas have a more complex role than the ones attributed by lesion studies, e.g. Broca's area in the left inferior frontal gyrus has been involved in speech production as well as in speech comprehension, and Wernicke's area located in the left temporoparietal area has been involved in language comprehension as well as phoneme discrimination (Friederici 2002; Luke et al. 2002). In addition, brain imaging studies showed that language processing is not restricted to Broca's and Wernicke's areas as shown by lesion studies, but requires a network of different brain areas which may be interconnected (Catani, Jones, and ffytche 2005; Behrens et al. 2003). However, the measures of brain activity implicate rather than demonstrate the critical contribution of a brain area to behavior, which can lead to misinterpretations.

\subsection{Basic principles of TMS}

During the last two decades, transcranial magnetic stimulation (TMS) has rapidly become a valuable method to investigate the human brain noninvasively (Siebner et al. 2009; Walsh and Rushworth 1999). TMS is based on electromagnetic induction: a change in electric current generates a magnetic field, which in turn induces a current in a second conductor brought into the magnetic field (Figure 1). 


\section{Magnetic field B}

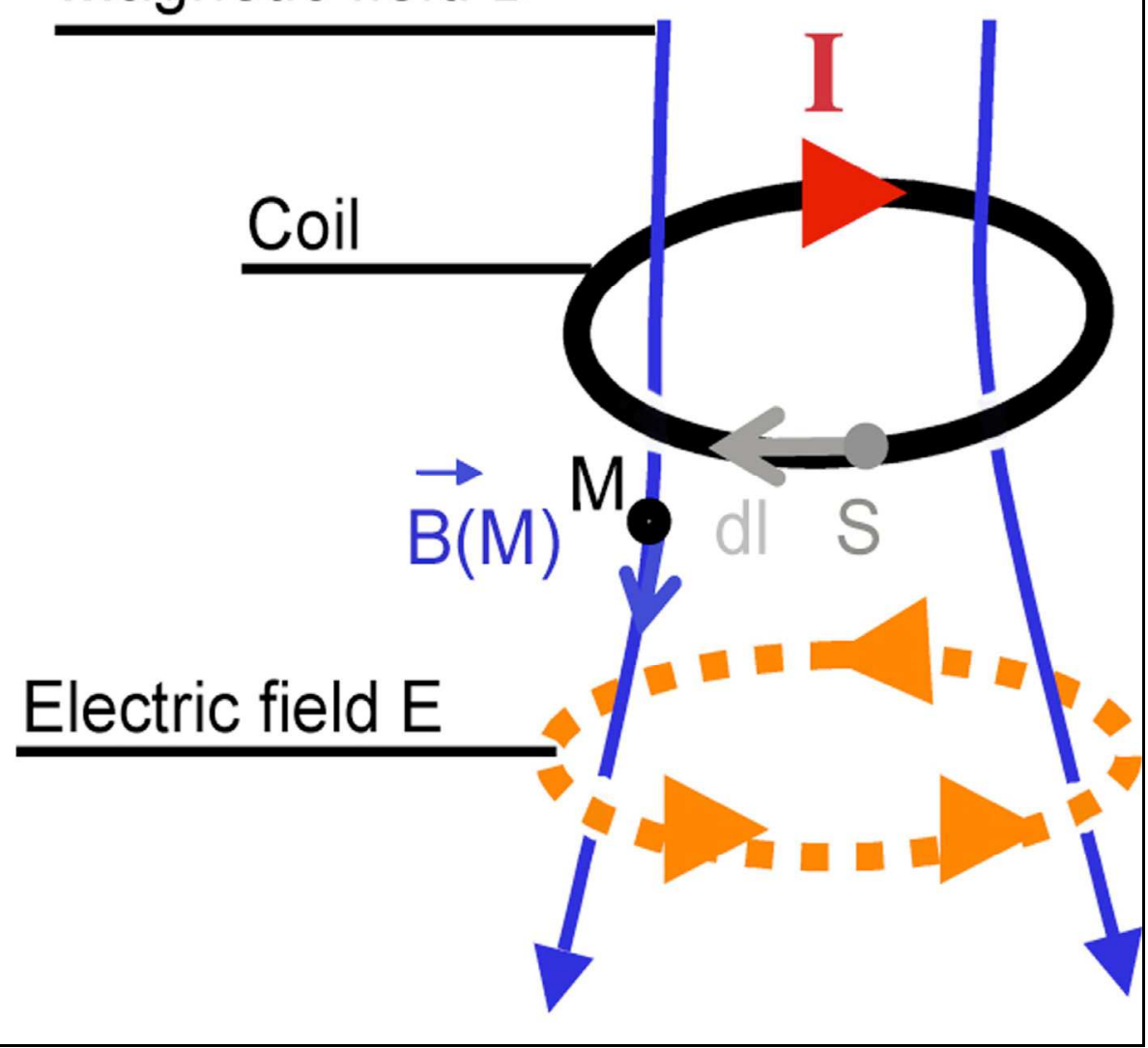

Fig. 1. an electric current (I) flowing through a coil of wire generates a magnetic field (B), which in turns induces electrical current in a secondary conductor.

The focality of stimulation with TMS depends on many factors such as the coil geometry (size and shape), the stimulus intensity or other external parameters such as the electrical properties of the cortex under the coil (Amassian et al., 1992; Cohen et al., 1990; Maccabee et al., 1993). The magnetic field induced by the TMS coil can be defined by the Biot-Savart law (see equation). The integration is performed with the vector $d \mathbf{l}$ along the coil windings Coil and $\mu 0$ is the permeability of free space (see Figure 1 ).

$$
\vec{B}(M)=\frac{\mu_{0}}{4 \pi} \oint_{\text {Coil }} \frac{\vec{I} d \vec{l} \wedge S \vec{M}}{\|S \vec{M}\|^{3}}
$$

The most common coils are the circular coil and the 8-shaped coil (see Figure 2), but recently developed coils (e.g. iron-core, Hesed or stereotactic) provide a more efficient and a deeper stimulation (Epstein and Davey 2002; Roth, Zangen, and Hallett 2002). 


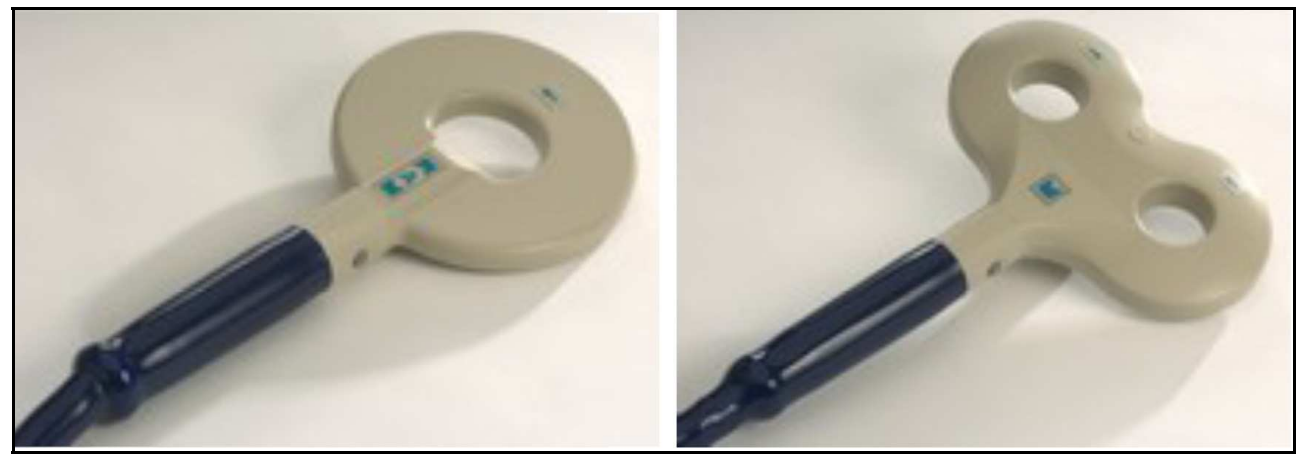

Fig. 2. The two most common TMS coils: (left) the circular coil and (right) the 8-shaped coil.

With a circular TMS coil (see Figure 2, left), the maximum electric field induced in the brain lies in an annulus under the coil (Figure 3). The 8-shaped coil is more focal than the circular coil (around $2 \mathrm{~cm}$ and $10 \mathrm{~cm}$ respectively) but in practice the circular coil is sometimes preferred over the 8-shaped coil because motor responses can be rapidly evoked without need for accurate coil positioning.

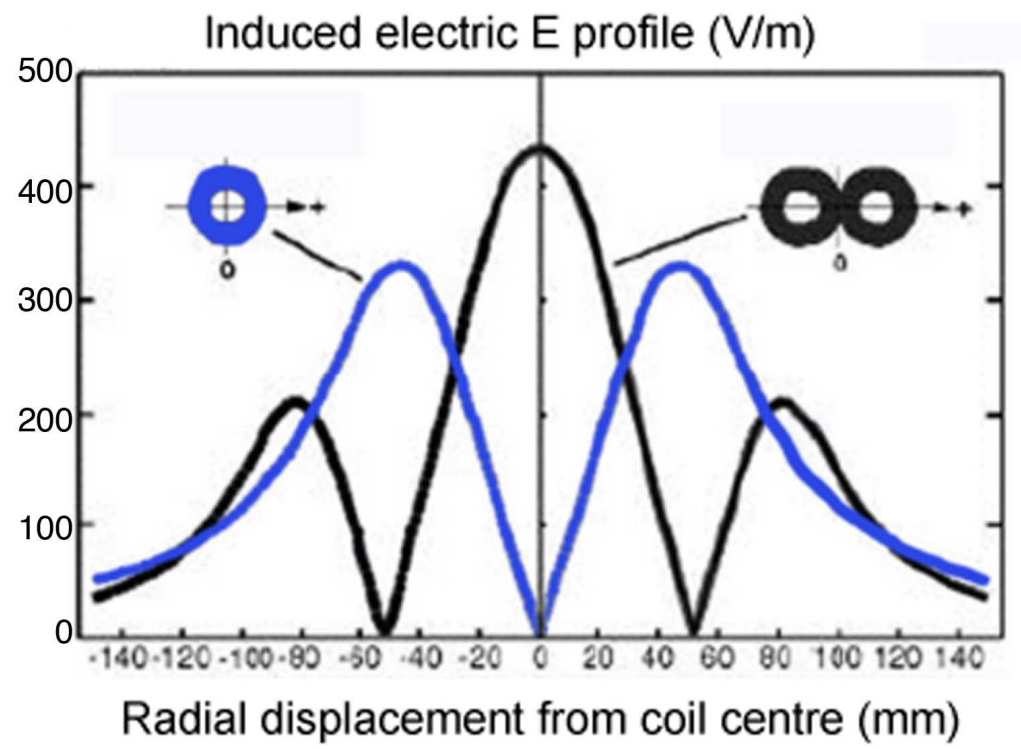

Fig. 3. Focality of the induced electric field for the circular coil (in blue) and for the 8-shaped coil (black). Data from constructor (Magstim Ltd., Wales, UK).

The focality and the strength of stimulation depend on the coil size and on the distance from the coil, both degrading quickly with increasing depth. As an indication, the field at a distance of $4 \mathrm{~cm}$ may be only about $30 \%$ of that at the coil surface as measured by Bohning et al. (1997) using fMRI and an MR-compatible TMS coil to map the magnetic field induced by the TMS coil in human volunteers. 


\subsection{TMS and interference with function}

By inducing a local electric field, TMS creates a "virtual lesion" that may transiently interfere with cognitive processing. This 'perturb and measure' approach provides a direct link between anatomy and function and could also infer causality in neural connectivity. When TMS is applied over the motor cortex, an immediate motor response is obtained and can be measured by motor evoked potentials. Depending on the frequency of stimulation, TMS has been reported either to excite or to inhibit cortical motor excitability. Low frequency rTMS $(<1 \mathrm{~Hz})$ on the motor cortex has been shown to result in an inhibition of corticomotor excitability (Chen et al. 1997; Muellbacher et al. 2000; Muellbacher et al. 2002), whereas high frequency rTMS $(>1 \mathrm{~Hz})$ has been associated with facilitation of corticomotor excitability. TMS-induced effects on cognitive functions can be quantified using indirect measures such as changes in behavioral performance during a cognitive task (e.g. response time or error rate). For example, Andoh et al. $(2006,2008)$ ) applied rTMS over the left temporoparietal area (TMP) of Wernicke and showed a reduced RT during an auditory task of word detection compared with rTMS applied over the left inferior frontal gyrus (IFG, pars opercularis). The authors attributed their findings to the modulation of the semantic processing associated with the left TMP and not with the left IFG. TMS-induced effects can also be directly quantified using fMRI or positron emission tomography (PET) to detect the changes in cerebral blood flow or metabolism respectively. For instance, in a consecutive study, Andoh and Paus (2011) carried out an fMRI scan before and after a series of TMS stimulations applied off-line over the left TMP area (i.e. TMS applied outside of the scanner bore). The comparison of fMRI data pre- and post-rTMS showed a local decrease of the neural activity in the left TMP area, and an increased neural activity in the contralateral right TMP. The authors hypothesized a mechanism of interhemispheric compensation for preserving behavior after a neural interference (for review Andoh and Martinot 2008)). Similar change in activity in language-related network was found by Thiel et al. (2006) reporting a CBF decrease in the stimulated left IFG and a CBF increase in the homologous (contralateral) right IFG during a verb-generation task. In addition, Ilmoniemi et al. (1997) reported comparable results using EEG. The authors showed that stimulation over visual or motor cortex elicits EEG responses around the site of stimulation within a few milliseconds of TMS, followed by responses from a secondary area of activity in the homotopic region of the contralateral hemisphere. These studies show that rTMS effects are not focal and confined to the site of stimulation, but spreads via pre-existing neuronal connections in a network, therefore making TMS a useful tool to investigate functional connectivity and plasticity in the normal brain (Paus et al. 1997; Siebner and Rothwell 2003) as well as in clinical population (Hampson and Hoffman 2010).

\subsection{TMS as a clinical treatment}

TMS has been investigated as a treatment tool in many neurological and psychiatric diseases, including epilepsy, Parkinson's disease, schizophrenia, or treatment-resistant depression. Because of its ability to modulate neural activity, rTMS has been used to excite or to inhibit certain brain functions reported to be "abnormal" in these patients. For instance, anatomic and functional dysfunctions in brain areas underlying speech generation and perception have been shown in schizophrenic patients prone to auditory hallucinations (Copolov et al. 2003; Shergill et al. 2000). Low frequency rTMS has been applied over the temporoparietal area of Wernicke; and this was shown to decrease its activity and to reduce 
auditory hallucinations in those patients (Hoffman et al. 2003). Regarding patients with treatment-resistant depression, neuroimaging studies have shown a reduced metabolism in the dorsolateral prefrontal cortex (DLPFC) in comparison with normal volunteers (George et al. 1995). In order to increase the DLPFC activity, TMS has been applied at high frequency (i.e. $10 \mathrm{~Hz}$ ) and results have shown an improvement in some patients. However, results vary among patients and across studies (Hoffman et al. 2003; O'Reardon et al. 2007, 2010). Different factors can account for this variability, such as the parameters of stimulation (frequency, intensity, duration), as well as differences between patients in anatomical and functional localization of areas stimulated.

\subsection{Importance of TMS coil placement}

The placement of the TMS coil above the proper site of the cortex is critical and several methods have been developed to control the positioning of the TMS coil. For example, some clinical studies have targeted the dorsolateral prefrontal cortex (DLPFC), Brodman's area (BA) 9 and 46, by positioning the coil $5 \mathrm{~cm}$ rostrally in the parasagittal plane from the motor cortex (Herwig et al. 2001; Pascual-Leone, Catala, and Pascual-Leone Pascual 1996), see Figure 4A. However, the DLPFC location using the "5-cm method" was found to correspond to Brodman's area (BA) 6 (premotor cortex) or BA 8 (frontal eye field) in 15/22 participants and only $7 / 22$ were correctly targeted for the stimulation of the DLPFC. As this was the method used to locate the left DLPFC in most studies, the high degree of variability in the stimulated target must surely affect clinical results (Herwig et al. 2001). Nauczyciel et al. (2010) evaluated the different sources of variability of this standard " $5-\mathrm{cm}$ method" and showed that interindividual anatomical variability and interexpert variability were the two main sources of error. In addition, Rusjan et al. (2010) developed a neuronavigational method based on a standard template and compared the location of the DLPFC with the " 5 -cm method" and the 10-20 EEG electrode system and found that the neuronavigational method and the 10-20 EEG electrode are superior to the " 5 -cm method" in reducing inter-subject variability.

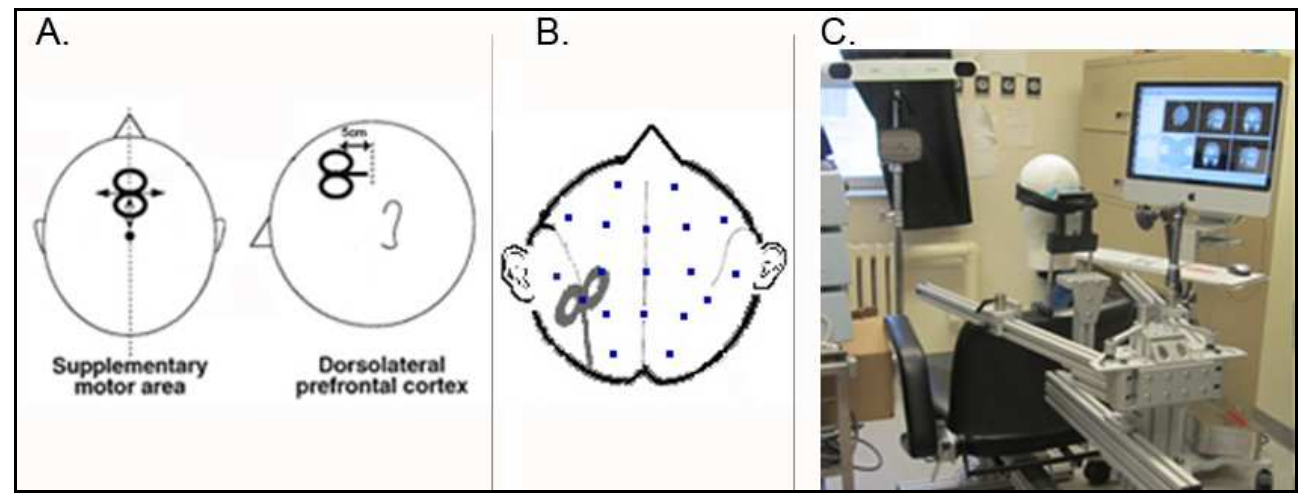

Fig. 4. Examples of methods used to localize the target for TMS. A. The DLPFC was targeted by moving the coil $5 \mathrm{~cm}$ forward from the motor cortex. B. Localization of the temporoparietal area of Wernicke using the 10-20 EEG system. C. Frameless stereotaxic system uses data from Magnetic Resonance Imaging to provide online monitoring of the TMS coil position on the participant's head (Rogue Research Inc.). 
Other studies used cranial coordinates in the international 10-20 electrode system (i.e. CP5) to localize Wernicke's area (Sparing et al. 2001), see Figure 4B. However, this standardized system does not take into account interindividual anatomo-functional variability of language organization, which depends on the side and degree of language lateralization (Knecht et al. 2000). To reduce the influence of such anatomo-functional variabilities between patients, frameless stereotaxic systems, used in conjunction with functional neuroimaging have been developed to target individual areas according to well-defined anatomo-functional landmarks (Figure 4C). These frameless stereotaxic systems offer a relatively high accuracy of coil positioning over targeted areas (of about 10mm) (Gugino et al. 2001; Lancaster et al. 2004). However, such systems are expensive, heavy and difficult to use in a clinical setting. A recent study compared the accuracy of neuronavigations systems and the 10-20 electrode system while targeting the right intraparietal sulcus (electrode P4) and found that 9 and 47 participants, respectively were sufficient to obtain significant behavioral results.

\section{Triangulation-based MRI-guided method}

More recently, some new methods have been developed to reliably and inexpensively position the TMS coil manually over the participant's head. Those MRI-guided methods are based on MRI data in order to take into account individual specificity in head size and shape, as well as in anatomical and functional differences between participants. We will describe a triangulation-based MRI-guided method that we have developed and validated (Andoh et al. 2009). We have evaluated its accuracy with the target of the motor cortex because its stimulation produces a measurable muscle twitch quantifiable with motor evoked potentials (MEPs). We also evaluated the reproducibility of the target positioning across operators while targeting the motor cortex and a target in the parietal cortex localized using fMRI during a mental rotation task. This method was recently used in a PET study investigating the influence of prefrontal target region on the efficacy of repetitive TMS in depressive patients resistant to treatment. The authors used a TMS target based on prefrontal hypometabolic regions defined for each patient using individual PET images (Paillere Martinot et al. 2010). In addition, this method was also used in an fMRI study investigating the TMS modulation of temporal areas during language processing (Andoh et al. 2006) or investigating the role of the frequency of TMS stimulation applied over temporoparietal areas (Andoh et al. 2008).

\subsection{Description of the MRI-guided method}

The MRI-guided method is included in Brainvisa software, freely available online (http://brainvisa.info/) that contains many image processing tools (segmentation of T1-weighted MR images, grey/white classification, meshes of hemisphere surface, etc.). Some of these tools were used in this paper to provide realistic and accurate 3D representations of the head surface and the brain, which enables easy definition of anatomic and functional landmarks in each subject (Riviere et al. 2002). In the following section, we will describe the procedure of the MRI-guided method, and then we will present the MRI protocol, which provides anatomical and functional MR images acquired during a simple motor task in order to individually define the target of the motor cortex onto the subject's head surface. A manual describing the step-by-step procedure is also provided at ftp://ftp.cea.fr/pub/dsv/anatomist/documents/TMS/Andoh_TMS-positioning.pdf. 


\subsection{Basis of the triangulation-based MRI-guided method}

The approach of the MRI-guided method is based on the triangulation (or "trilateration"), consisting in determining the relative position of a target $(\mathrm{T})$ using the known locations of two or more reference points $(\mathrm{A}, \mathrm{B}, \mathrm{C})$ and the distance between the target and each reference point $d_{i}(i=A, B, C)$. When measurement error is introduced, if we know that the distance from the target $\mathrm{T}$ to a reference point $\mathrm{i}(=\mathrm{A}, \mathrm{B}$ or $\mathrm{C})$ lies within a range of distance $\left[\mathrm{d}_{\mathrm{i}}+\mathrm{dr}\right]$, then the third point lies in a circular band between the circles of those two radii. If we know a range for another point, we can take the intersection, which will be either one or two areas bounded by circular arcs (Figure 5). A third point will narrow it down to a smaller area, which therefore limits the variability of the target positioning (Snyman 2005).

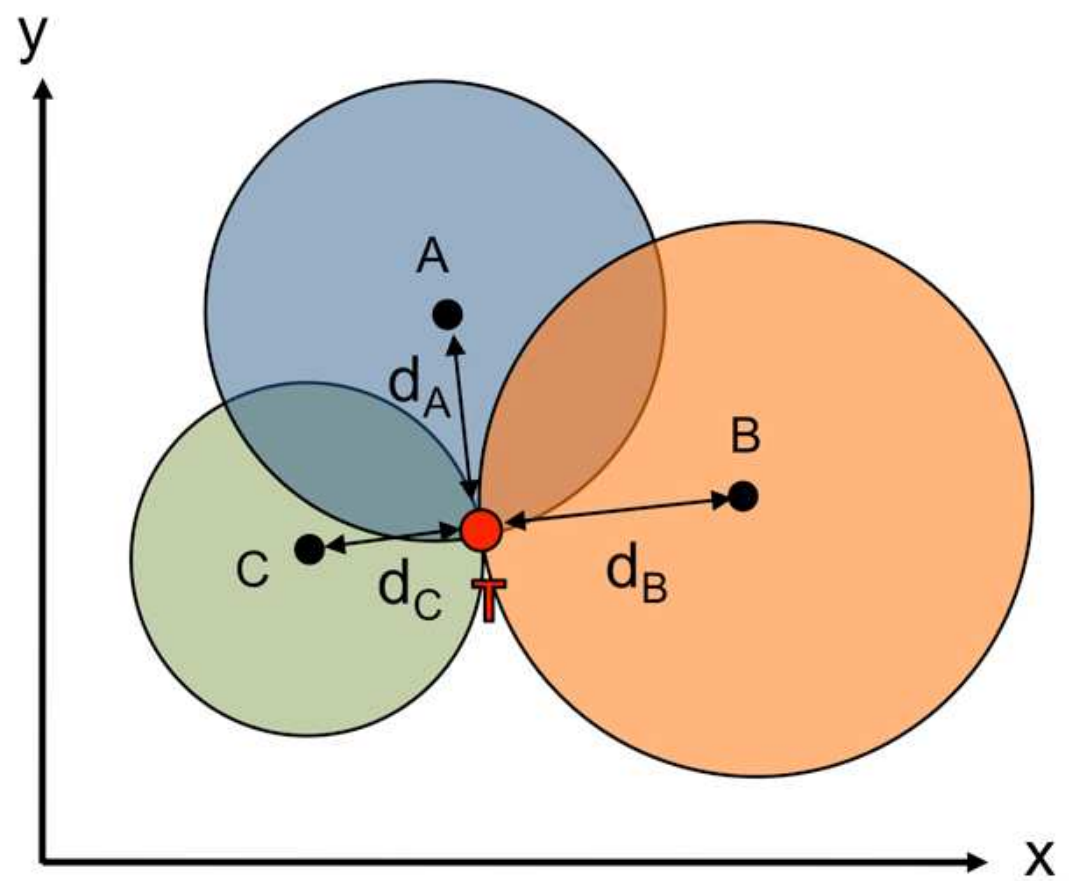

Fig. 5. Determination of the relative position of a target $(\mathrm{T})$ using the known locations of three reference points $(\mathrm{A}, \mathrm{B}, \mathrm{C})$ and the distance between the target and each reference point $\left(\mathrm{d}_{\mathrm{A}}, \mathrm{d}_{\mathrm{B}}, \mathrm{d}_{\mathrm{C}}\right)$.

\subsection{Procedure of the MRI-guided method}

Some preprocessing steps need to be carried out on the MR anatomical images before using the MRI-guided procedure. First, a "bias analysis" is carried out to correct the standard inhomogeneities in MR images using a bias estimation for each subject (http://www.brainvisa.info/doc/brainvisa/en/processes/VipBiasCorrection.html).

Second, the "histogram analysis" leads to estimations of the gray and white matter mean and standard deviations. It relies on a scale-space analysis of the histogram, which is robust to 
modifications of the MR sequence (Mangin, Coulon, and Frouin 2005). Third, the "brain segmentation" uses the parameters given by the previous step to segment the brain (Mangin et al. 2004). The segmentation of the head surface was carried out and MR images were thresholded from the intensity histogram. Then, a morphologic closing was applied to fill up cavities and holes on the head reconstruction and the resulting mesh object was smoothed using a marching-cube algorithm (Figure 6. A, B).

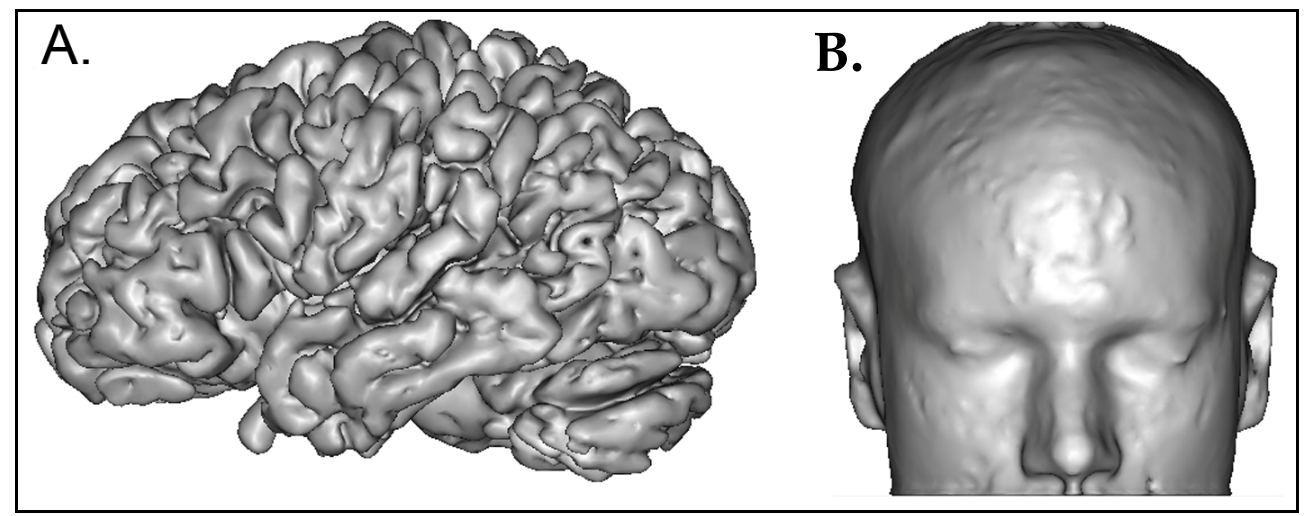

Fig. 6. Segmentation of the brain and head providing 3D reconstruction of $\mathrm{A} /$ the brain and B/ head surfaces.

Once those steps have been processed, the MRI-guided procedure can be carried out following three steps:

1. The first step "target projection" consists in the projection of a cortical target (e.g. maximum peak of cortical activation) onto a 3D head mesh (see Figure 7). This step is particularly crucial as inaccuracy in head surface reconstruction may induce local geometric artefacts, and the target projection onto the head surface may be confounded. To obtain a robust projection of the cortical target onto the head surface, we used the centre of gravity of the $(\mathrm{N}=10)$ closest head mesh nodes (Andoh et al. 2006).
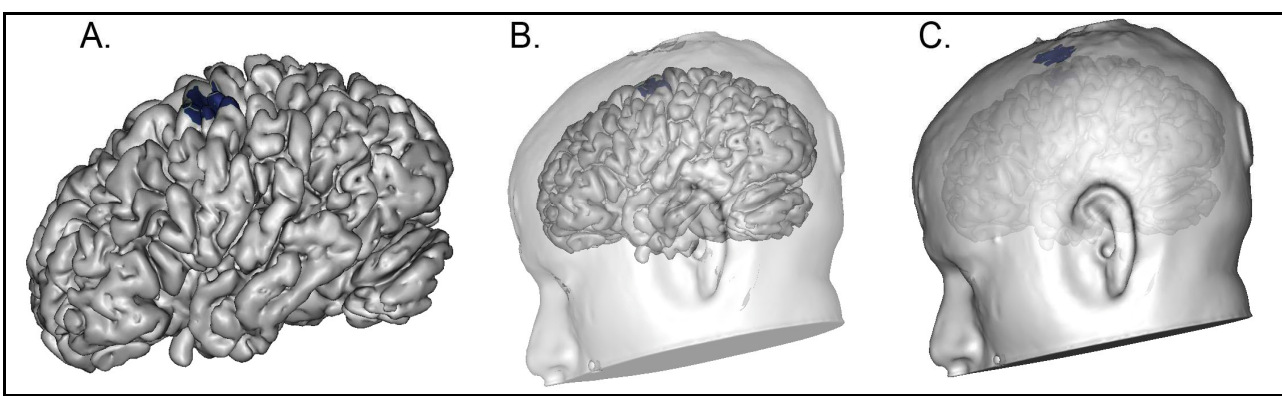

Fig. 7. 3D visualization of a functional target on A/ a brain mesh, B/ a brain mesh with the transparent head surface, and C/ projection of the functional target onto a 3D head surface.

2. The next step consists in computing the geodesic distances (i.e. tangent to the head surface) between the projected target on the head mesh surface and some landmarks on 
the subject's head (nose bridge, tragus of both ears, Figure 8). This was done using an algorithm available in Brainvisa software (see manual for more information, ftp:/ /ftp.cea.fr/pub/dsv/anatomist/documents/TMS/Andoh_TMS-positioning.pdf).

Three geodesic distances (in $\mathrm{mm}$ ) were obtained from the target to the nasion, and from the target to the left and right tragi of both ears providing three distances for the triangulation.

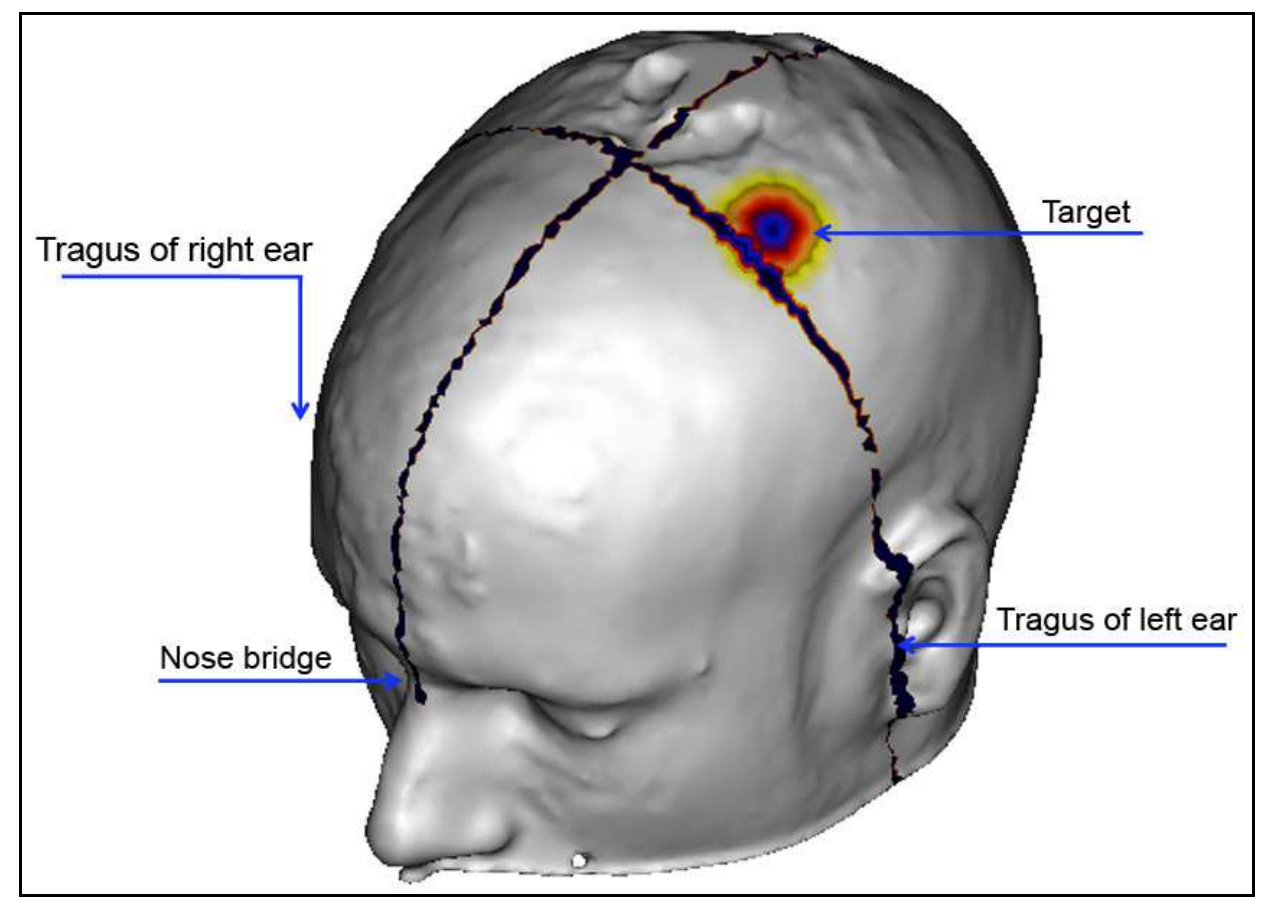

Fig. 8. Positioning of the three head landmarks on the 3D head reconstruction relative to the target location (nose bridge, tragi of both ears).

3. The final step consists in using these three geodesic distances to localize the cortical target onto the participant's head. The point of intersection of the three distances provides the target in order to position the TMS coil; and this position was marked physically on the cap of each participant (Figure 9). The triangulation was done manually, by the same investigator (JA) for all subjects, using three tied threads of lengths equal to the three geodesic distances.

\subsection{Accuracy of the method}

To assess the accuracy of the method, we used the cortical target of the hand motor area as its stimulation with TMS provides quantitative responses with motor-evoked potentials (Boroojerdi et al. 1999). The cortical target of the hand motor area was defined by the peak of task-related activity while participants were pressing left and right buttons inside an MR scanner. The difference between right and left thumb motor responses provided the location of the left motor cortical area (Figure 10). 


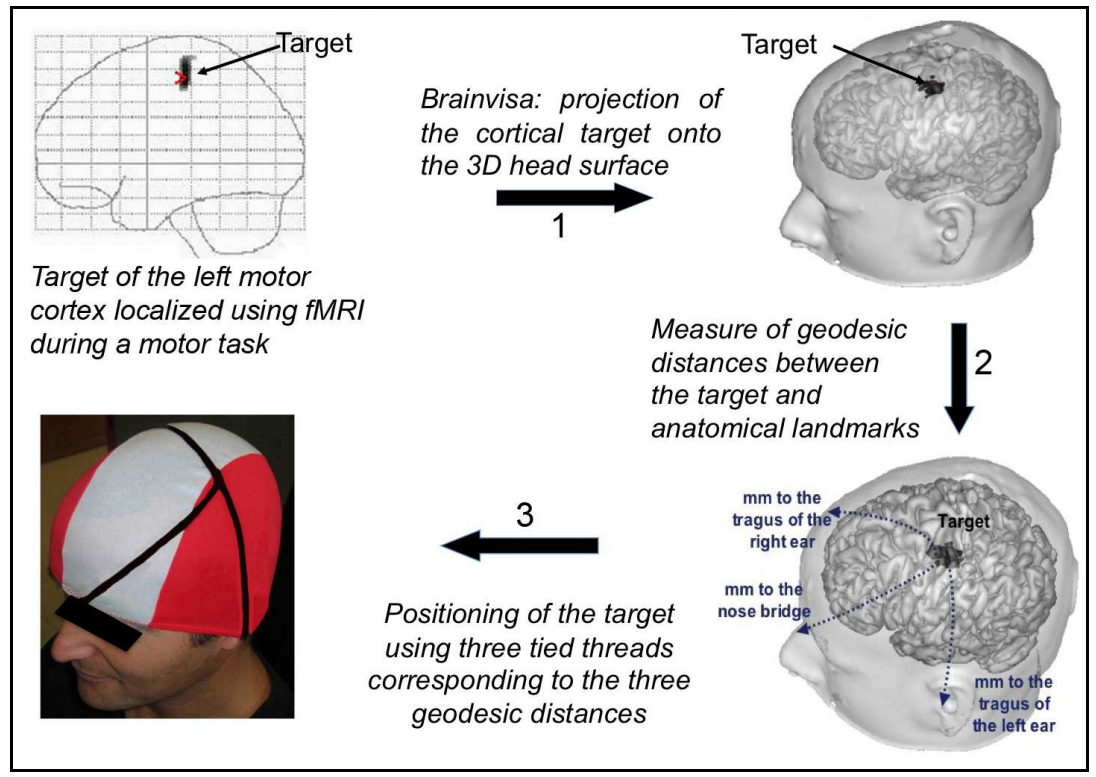

Fig. 9. Illustration of the three steps composing the MRI-guided method. 1/ projection of the cortical target of the motor cortex on a 3D head rendering. 2/ Measure of the geodesic distances (tangent to head surface) between the target and some landmarks on the subject's head (e.g. nose bridge and tragus of both ears). 3/ Positioning of the geodesic distances on the participant's head using three tied threads corresponding to the three distances. The intersection of the three tied threads provided the target location for TMS coil positioning.

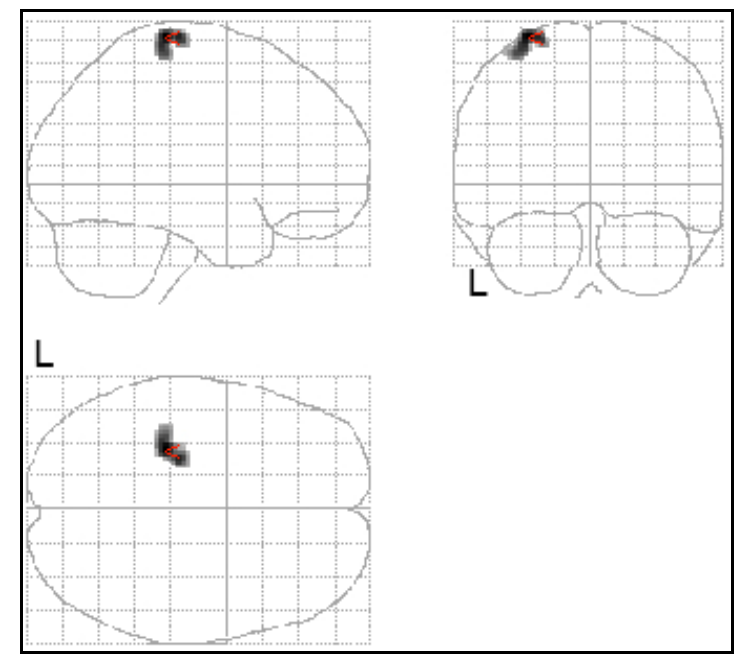

Fig. 10. Definition of the cortical target of the left motor cortical area. The target was defined by the peak of activation resulting from the contrast between right and left thumb motor responses (FWE-corrected; cluster size threshold $\mathrm{p}<0.001$ ). 
The accuracy of the method was determined by comparing the coil position over the right thumb motor target obtained from the MRI-guided method (fMRI-target) and the coil position subsequently obtained, where reproducible thumb motor-evoked potentials (MEPs) were elicited from TMS (MEP-target). The 3D coordinates of the two positions (fMRI-target and MEP-target) were obtained with an optical tracking system included in Brainsight ${ }^{\mathrm{TM}}$ Frameless. For each participant, the location of the fMRI- and MEP-targets was determined using individual coordinates in native space. Those coordinates were then transformed in standard space for group comparisons.

\subsection{Measures of motor-evoked potentials in motor cortex with TMS}

The MEP target (the target position that elicits MEPs in response to magnetic stimulation) was defined by the motor threshold criteria (MT), namely the lowest intensity of stimulation for evoking at least five MEPs in a total of ten stimulations with amplitude superior to 50 $\mu \mathrm{V}$. A surface electromyogram EMG (Keypoint Portable, Medtronic) was used to record MEP amplitude from the relaxed right abductor pollicis brevis (Pascual-Leone et al. 1993; Rossini et al. 1995; Rothwell et al. 1999), see Figure 11. Magnetic stimulation was applied with a MagPro Stimulator (http://www.medtronic.com). Stimulus intensity started at 50\% of the stimulator output and was increased in steps of $1 \%$ stimulator output.

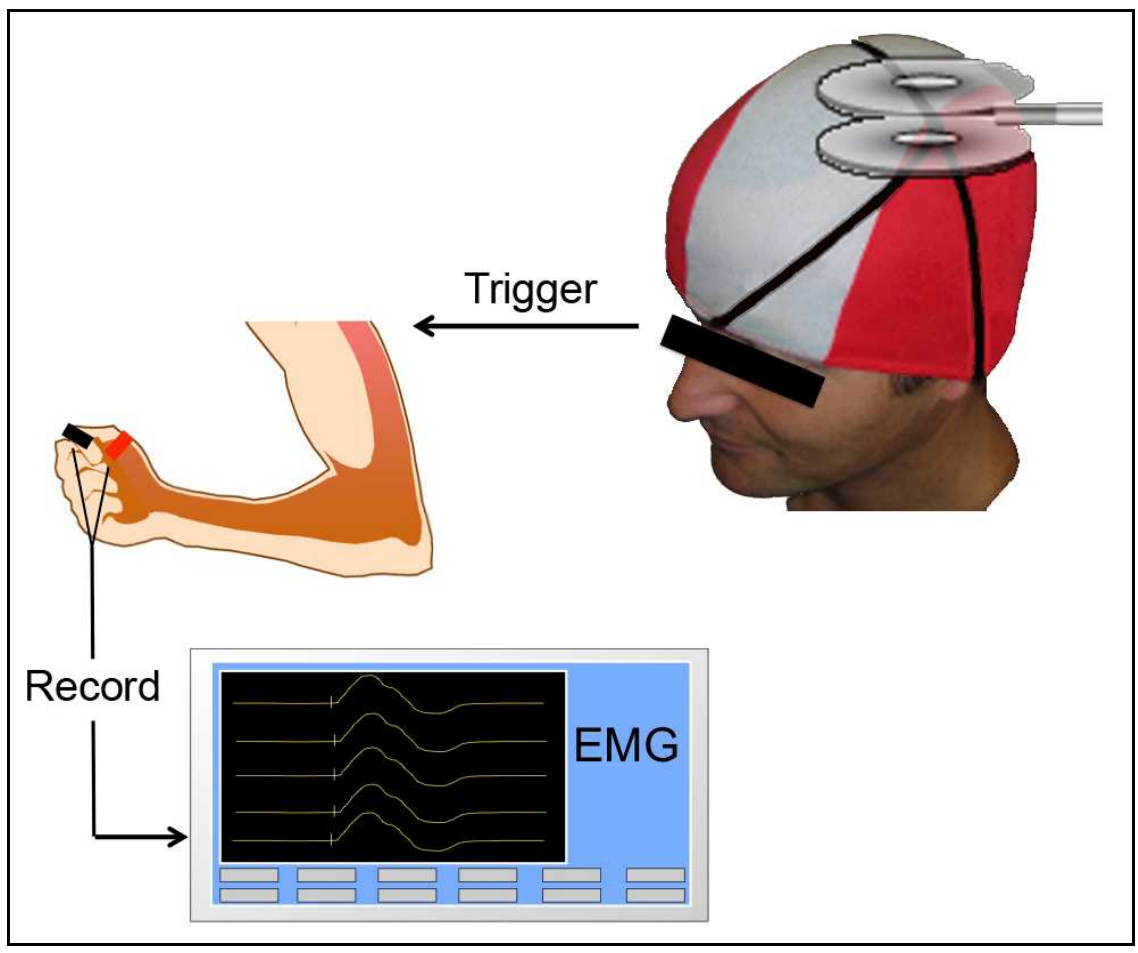

Fig. 11. Recording of motor evoked potentials (MEPs) in response to TMS using an electromyogram (EMG). The MEP target was defined by the lowest intensity of stimulation that induces at least five MEP with an amplitude $>50 \mu \mathrm{V}$ in a total of ten stimulations. 
We compared the coil position over the right thumb motor target obtained from the MRIguided method (fMRI-target) with the coil position obtained subsequently, eliciting reproducible MEPs with stimulation (MEP-target), see Figure 12. For each subject, the coordinates of the coil positions over the fMRI-target $\left(\mathrm{x}_{\mathrm{fMRI}}, \mathrm{y}_{\mathrm{fMRI}}, \mathrm{z}_{\mathrm{fMRI}}\right)$ and the MEP-target ( $\mathrm{x}_{\mathrm{MEP}}, \mathrm{y}_{\mathrm{MEP}}, \mathrm{z}_{\mathrm{MEP}}$ ) were recorded using an optical tracking system and compared using the mean Euclidean distance (D):

$$
\mathrm{D}=\left[\left(\mathrm{x}_{\mathrm{fMRI}}-\mathrm{x}_{\mathrm{MEP}}\right)^{2}+\left(\mathrm{y}_{\mathrm{fMRI}}-\mathrm{y}_{\mathrm{MEP}}\right)^{2}+\left(\mathrm{z}_{\mathrm{fMRI}}-\mathrm{z}_{\mathrm{MEP}}\right)^{2}\right]^{1 / 2}=\left[\mathrm{D}_{\mathrm{x}}^{2}+\mathrm{D}_{\mathrm{y}^{2}}+\mathrm{D}_{\mathrm{z}}{ }^{2}\right]^{1 / 2} .
$$

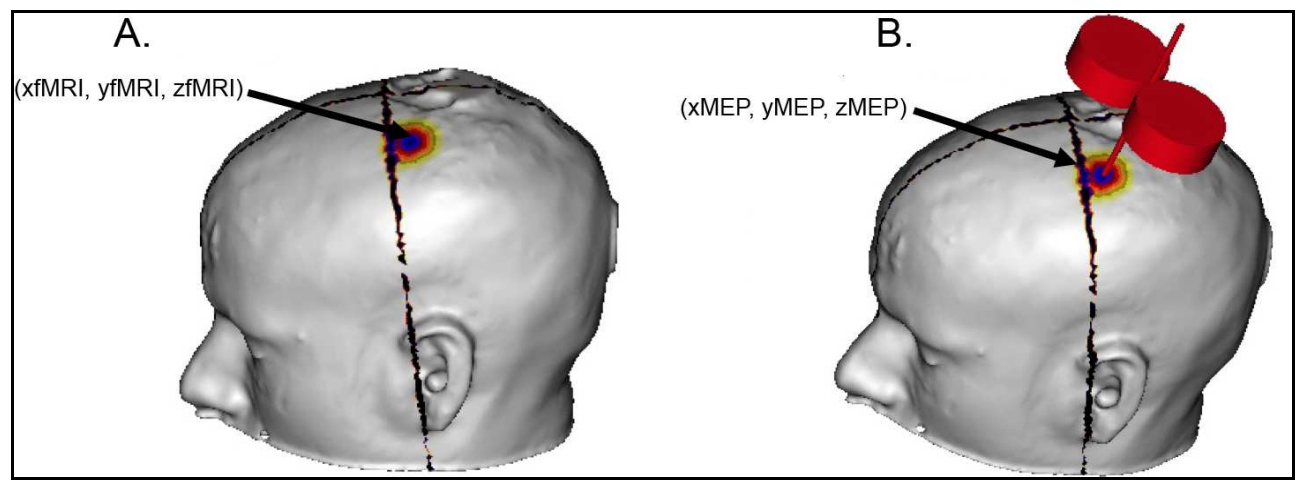

Fig. 12. Locations of A/ the fMRI-target (xfMRI, yfMRI, zfMRI) and B/ the MEP-target (xMEP, yMEP, zMEP) on a 3D head surface. The coordinates of both locations were recorded using an optical tracking system and compared using the mean Euclidean distance.

\subsection{Reproducibility}

The reproducibility of the target positioning was evaluated between operators by localizing the target of the motor cortex (see section above) and another target, located more posteriorly in the right parietal cortex. This target was functionally defined using a mental rotation task similar to the one used by Cooper and Shepard (1973). The mental rotation task consisted in displaying visually presented asymmetrical alphabetic characters (L, G, a), which had to be judged either normal or mirror image after rotation at different angular orientations. A "resting" condition was added in which subjects were asked to maintain their gaze on a small centrally located crosshair. The contrast between the task-related activity during the mental rotation task, and the resting condition enabled us to find the location of the right parietal cortex in each participant (Figure 13). Two operators used the MRI-guided method blindly and independently to position consecutively the targets of the motor cortex and the right parietal area over the cap of each subject's head. The difference between the locations determined by the two operators was measured by the mean Euclidean distance (see section above). 

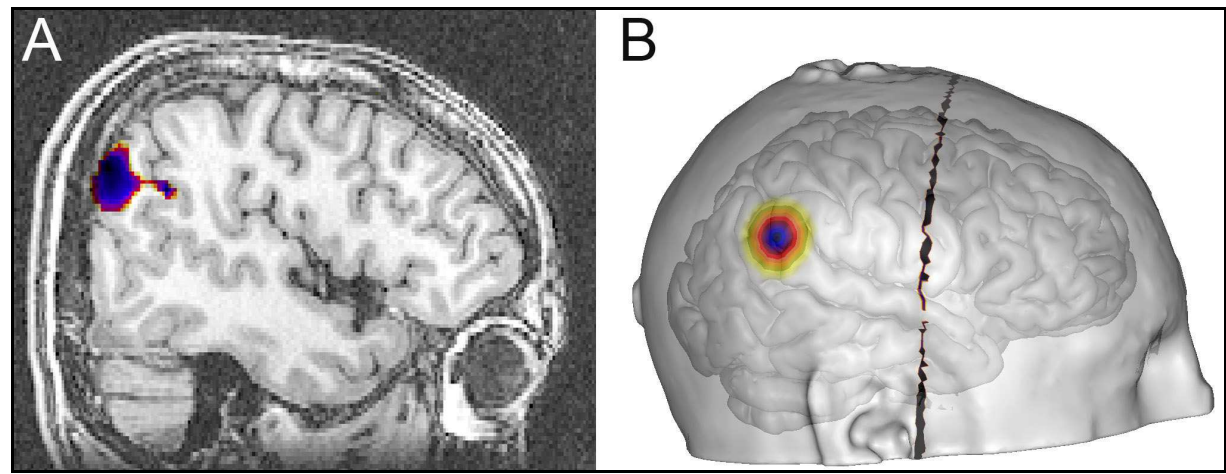

Fig. 13. Definition of a target in the right parietal cortex localized using fMRI during a mental rotation task. A/ location of the task-related activity on a $2 \mathrm{D}$ transverse view, and B/ projection of the target onto a $3 \mathrm{D}$ head reconstruction.

\section{Results}

\subsection{Accuracy}

The mean Euclidean distance (mean \pm SD) between the fMRI and the MEP targets was measured for ten participants in their individual spaces and was then transformed in the standard space (MNI, Montreal Neurological Institute) for group analysis (Table 1). The cortical target derived from fMRI during the motor task allowed for determination of the motor threshold in two subjects with an MEP amplitude $>50 \mu \mathrm{V}$ in 6 out of 10 trials. The mean Euclidean distance (mean $\pm S D$ ) between the fMRI and the MEP targets was $D_{m}=10.1 \pm$ $2.9 \mathrm{~mm}$, ranging from 5.2 to $14.0 \mathrm{~mm}$. The components of this distance in the $\mathrm{x}, \mathrm{y}$, and z-axes were $\mathrm{D}_{\mathrm{x}}=4.0 \pm 2.2 \mathrm{~mm}$ (range $0.6-7.7 \mathrm{~mm}$ ), $\mathrm{D}_{\mathrm{y}}=5.0 \pm 2.5 \mathrm{~mm}$ (range $1.3-8.0 \mathrm{~mm}$ ) and $\mathrm{D}_{\mathrm{z}}=$ $7.1 \pm 3.0 \mathrm{~mm}$ (range $2.8-11.1 \mathrm{~mm}$ ).

\begin{tabular}{cccccc}
\hline \multirow{5}{*}{ Subjects } & \multicolumn{3}{c}{ Euclidean distances } & & \\
& $\mathrm{D}_{\mathrm{x}}$ & $\mathrm{D}_{\mathrm{y}}$ & $\mathrm{D}_{\mathrm{z}}$ & & Motor threshold (\%SO) \\
\hline $\mathrm{S} 1$ & 7.0 & 4.9 & 5.4 & 10.1 & 50 \\
$\mathrm{~S} 2$ & 1.8 & 5.7 & 3.2 & 6.7 & 58 \\
$\mathrm{~S} 3$ & 3.7 & 5.1 & 10.0 & 11.9 & 58 \\
$\mathrm{~S} 4$ & 4.0 & 8.1 & 8.8 & 12.6 & 51 \\
$\mathrm{~S} 5$ & 3.9 & 7.8 & 9.1 & 12.6 & 60 \\
$\mathrm{~S} 6$ & 3.2 & 1.3 & 3.9 & 5.2 & 56 \\
$\mathrm{~S} 7$ & 7.7 & 1.8 & 2.8 & 8.4 & 61 \\
S8 & 5.4 & 6.7 & 11.1 & 14.0 & 56 \\
S9 & 0.6 & 6.9 & 9.3 & 11.6 & 63 \\
S10 & 3.2 & 1.8 & 7.3 & 8.2 & \\
\hline
\end{tabular}

Table 1. Euclidean distances between the fMRI target and the MEP target in the $\mathrm{x}$ axis $\left(\mathrm{D}_{\mathrm{x}}\right), \mathrm{y}$ axis $\left(D_{y}\right)$, and $z$ axis $\left(D_{z}\right)$. $D_{m}$ is the mean Euclidean distance for each participant averaged across $\mathrm{x}, \mathrm{y}$ and $\mathrm{z}$ axes. The last column is the motor threshold expressed in percentage of stimulator output (\%SO). 


\subsection{Reproducibility}

The results of the repositioning of the motor cortex target across two different operators showed a mean Euclidean distance of $6.7 \pm 1.4 \mathrm{~mm}$, ranging from 5.4 to $8.3 \mathrm{~mm}$. In all subjects, the MRI-guided method allowed operators to induce a motor response. The results of the repositioning over the right parietal target across operators was determined on four subjects, and showed a mean Euclidean distance of $6.0 \pm 3.2 \mathrm{~mm}$, ranging from 1.4 to 8.7 $\mathrm{mm}$.

\section{Limitations}

Different sources of variability should be considered in the evaluation of this method. First the definition of the tragi of both ears and the nose bridge are anatomic structures on the order of 1 $\mathrm{cm}$ diameter, and is therefore operator-dependent. Second, the coil positioning over the target cannot be controlled because once the coil is positioned, we cannot verify the location of the centre of coil. In addition, despite our results are interpreted as evidencing distance differences between the two methods (fMRI and MEP), it is also possible that results reflect the fact that the motor-related response obtained by fMRI and the motor evoked responses induced by TMS are not directly comparable (Lotze et al., 2003; Herwig et al., 2002). Indeed, TMS is activating all excitable circuits within the volume reached by the induced current, whereas fMRI measures increased oxygen supply in capillaries adjacent to neural firing. Since the responses probably do not involve the exact same tissue area, it is possible that they do not imply the same exact spatial representation in the primary motor cortex. Another limiting factor is the assumption that the induced electrical field is the strongest at the center of the figure of eight coil, however the depolarized neurons may not be directly beneath the center of the coil as has been indicated in other studies (Siebner et al., 2009; George et al., 2003), therefore introducing a variability in the concordance of the validation methods.

More recently, similar methods have been developed, showing the crucial need for relatively cheap and straightforward image-guided systems that can be used in the absence of neuronavigation. For instance, Rusjan et al. (2010) developed a manual method based on a standard template to target the left dorsolateral prefrontal cortex in each participant. They reported that the 'neuronavigational method' for localizing the DLPFC provided less intersubject variability compared with the ' $5-\mathrm{cm}$ method' or the ' $10-20$ method'. In addition, Weiduschat et al. (2009) developed a surface distance measurements (SDM) method and evaluated its accuracy by comparison with a neuronavigation system. They reported a mean Euclidean distance of $8.3 \mathrm{~mm}$ between their method and the neuronavigation system while targeting Broca's area. However, similarly to our method, these methods do not provide an online guiding of TMS coil positions.

\section{Conclusions}

The MRI-guided method provides a relatively accurate and a low cost solution for TMS coil positioning. We found an accuracy of $10 \pm 3 \mathrm{~mm}$ for positioning the target of the motor cortex, which is comparable to the accuracy of neuronavigation systems, for instance $10 \pm 8 \mathrm{~mm}$ (Gugino et al. 2001), $10 \pm 3 \mathrm{~mm}$ (Lancaster et al. 2004). This accuracy is also consistent with the focality of the TMS coil (e.g. $2-3 \mathrm{~cm}^{2}$, (Thielscher and Kammer 2004). In comparison to neuronavigation systems, the MRI-guided method is relatively inexpensive and does not require any additional setup, which makes it particularly useful for therapeutic protocols 
conducted at more than one medical center. In addition, the present method is user-friendly and only needs Brainvisa, a software free available on-line. Moreover, a major advantage of this method is its ability to target cortical landmarks anywhere in the whole brain, whereas neuronavigation systems are limited by the field of view of the tracking cameras and cannot localize targets in the occipital cortex. We also showed that this method is reproducible across operators to localize a target in the parietal cortex, with a mean reproducibility of $7 \pm 1 \mathrm{~mm}$. However, a main limitation of our method is its inability to provide an online monitoring of TMS coil shifts and orientations, particularly useful for long period of stimulations.

\section{Acknowledgment}

JA was supported by the French Foundation for Medical Research. We thank R.M. Comeau (Rogue Research Inc., Montreal, Ca; http://www.rogue-research.com) for advice regarding the plugging of the neuronavigation system with Brainvisa software.

\section{References}

Andoh, J., E. Artiges, C. Pallier, D. Riviere, J. F. Mangin, A. Cachia, M. Plaze, M. L. PaillereMartinot, and J. L. Martinot. 2006. Modulation of language areas with functional MR image-guided magnetic stimulation. Neuroimage 29 (2):619-27.

Andoh, J., E. Artiges, C. Pallier, D. Riviere, J. F. Mangin, M. L. Paillere-Martinot, and J. L. Martinot. 2008. Priming frequencies of transcranial magnetic stimulation over Wernicke's area modulate word detection. Cereb Cortex 18 (1):210-6.

Andoh, J., and J. L. Martinot. 2008. Interhemispheric compensation: a hypothesis of TMSinduced effects on language-related areas. Eur Psychiatry 23 (4):281-8.

Andoh, J., D. Riviere, J. F. Mangin, E. Artiges, Y. Cointepas, D. Grevent, M. L. PaillereMartinot, J. L. Martinot, and A. Cachia. 2009. A triangulation-based magnetic resonance image-guided method for transcranial magnetic stimulation coil positioning. Brain Stimulation 2 (3):123-131.

Behrens, T. E., M. W. Woolrich, M. Jenkinson, H. Johansen-Berg, R. G. Nunes, S. Clare, P. M. Matthews, J. M. Brady, and S. M. Smith. 2003. Characterization and propagation of uncertainty in diffusion-weighted MR imaging. Magn Reson Med 50 (5):1077-88.

Bestmann, S., J. Baudewig, H. R. Siebner, J. C. Rothwell, and J. Frahm. 2003. Is functional magnetic resonance imaging capable of mapping transcranial magnetic cortex stimulation? Supplements to Clinical neurophysiology 56:55-62.

Bohning, D. E., A. P. Pecheny, C. M. Epstein, A. M. Speer, D. J. Vincent, W. Dannels, and M. S. George. 1997. Mapping transcranial magnetic stimulation (TMS) fields in vivo with MRI. Neuroreport 8 (11):2535-8.

Boroojerdi, B., H. Foltys, T. Krings, U. Spetzger, A. Thron, and R. Topper. 1999. Localization of the motor hand area using transcranial magnetic stimulation and functional magnetic resonance imaging. Clin Neurophysiol 110 (4):699-704.

Broca, P.M., 1861. Remarques sur le siège de la faculté de langage articulé, suivies d'une observation d'aphémie (perte de parole). Bull. Mem. Soc. Anat. Paris 36, 330-357.

Catani, M., D. K. Jones, and D. H. ffytche. 2005. Perisylvian language networks of the human brain. Annals of neurology 57 (1):8-16.

Chen, R., J. Classen, C. Gerloff, P. Celnik, E. M. Wassermann, M. Hallett, and L. G. Cohen. 1997. Depression of motor cortex excitability by low-frequency transcranial magnetic stimulation. Neurology 48 (5):1398-403. 
Cooper, A.N., and R.N. Shepard. 1973. The time required to prepare for a rotated stimulus. Memory $\mathcal{E}$ Cognition 1:246-250.

Copolov, D. L., M. L. Seal, P. Maruff, R. Ulusoy, M. T. Wong, H. J. Tochon-Danguy, and G. F. Egan. 2003. Cortical activation associated with the experience of auditory hallucinations and perception of human speech in schizophrenia: a PET correlation study. Psychiatry research 122 (3):139-52.

Epstein, C. M., and K. R. Davey. 2002. Iron-core coils for transcranial magnetic stimulation. Journal of clinical neurophysiology: official publication of the American Electroencephalographic Society 19 (4):376-81.

Friederici, A. D. 2002. Towards a neural basis of auditory sentence processing. Trends in cognitive sciences 6 (2):78-84.

Frith, C.D. \& Friston K.J. 1997. Studying brain function with neuroimaging. Cognitive Neuroscience ed. M.D.Rugg (Psychology Press: Hove UK.):169-195.

George, M. S., E. M. Wassermann, W. A. Williams, A. Callahan, T. A. Ketter, P. Basser, M. Hallett, and R. M. Post. 1995. Daily repetitive transcranial magnetic stimulation (rTMS) improves mood in depression. Neuroreport 6 (14):1853-6.

George ,M.S., Z. Nahas, S. H. Lisanby, T. Schlaepfer, F. A. Kozel, B. D. Greenberg. 2003. Transcranial magnetic stimulation. Neurosurg Clin N Am 14:283-301.

Gugino, L. D., J. R. Romero, L. Aglio, D. Titone, M. Ramirez, A. Pascual-Leone, E. Grimson, N. Weisenfeld, R. Kikinis, and M. E. Shenton. 2001. Transcranial magnetic stimulation coregistered with MRI: a comparison of a guided versus blind stimulation technique and its effect on evoked compound muscle action potentials. Clinical neurophysiology: official journal of the International Federation of Clinical Neurophysiology 112 (10):1781-92.

Hampson, M., and R. E. Hoffman. 2010. Transcranial magnetic stimulation and connectivity mapping: tools for studying the neural bases of brain disorders. Frontiers in systems neuroscience 4.

Herwig, U., F. Padberg, J. Unger, M. Spitzer, and C. Schönfeldt-Lecuona. 2001. Transcranial magnetic stimulation in therapy studies: examination of the reliability of "standard" coil positioning by neuronavigation. Biological psychiatry 50 (1):58-61.

Herwig U., K. Kolbel, A.P. Wunderlich, A. Thielscher, C. von Tiesenhausen, M. Spitzer and C. Schönfeldt-Lecuona. 2002. Spatial congruence of neuronavigated transcranial magnetic stimulation and functional neuroimaging, Clin. Neurophysiol. 113:462-468.

Hoffman, R. E., K. A. Hawkins, R. Gueorguieva, N. N. Boutros, F. Rachid, K. Carroll, and J. H. Krystal. 2003. Transcranial magnetic stimulation of left temporoparietal cortex and medication-resistant auditory hallucinations. Archives of general psychiatry 60 (1):49-56.

Ilmoniemi, R. J., J. Virtanen, J. Ruohonen, J. Karhu, H. J. Aronen, R. Naatanen, and T. Katila. 1997. Neuronal responses to magnetic stimulation reveal cortical reactivity and connectivity. Neuroreport 8 (16):3537-40.

Knecht, S., M. Deppe, B. Drager, L. Bobe, H. Lohmann, E. Ringelstein, and H. Henningsen. 2000. Language lateralization in healthy right-handers. Brain 123 ( Pt 1):74-81.

Lancaster, J. L., S. Narayana, D. Wenzel, J. Luckemeyer, J. Roby, and P. Fox. 2004. Evaluation of an image-guided, robotically positioned transcranial magnetic stimulation system. Human brain mapping 22 (4):329-40.

Lotze, M., R.J. Kaethner, M. Erb, L.G. Cohen, W. Grodd, and H. Topka. 2003. Comparison of representational maps using functional magnetic resonance imaging and transcranial magnetic stimulation, Clin. Neurophysiol. 114:306-312. 
Luke, K. K., H. L. Liu, Y. Y. Wai, Y. L. Wan, and L. H. Tan. 2002. Functional anatomy of syntactic and semantic processing in language comprehension. Human brain mapping 16 (3):133-45.

Mangin, J. F., D. Riviere, A. Cachia, E. Duchesnay, Y. Cointepas, D. Papadopoulos-Orfanos, P. Scifo, T. Ochiai, F. Brunelle, and J. Regis. 2004. A framework to study the cortical folding patterns. NeuroImage 23 Suppl 1:S129-38.

Mangin, J.F., O. Coulon, and V. Frouin. 2005. Robust brain segmentation using histogram scale-space analysis and mathematical morphology. In Proc. 1st MICCAI, LNCS1496, MIT, Boston,:1230-1241.

Muellbacher, W., U. Ziemann, B. Boroojerdi, and M. Hallett. 2000. Effects of low-frequency transcranial magnetic stimulation on motor excitability and basic motor behavior. Clinical neurophysiology: official journal of the International Federation of Clinical Neurophysiology 111 (6):1002-7.

Muellbacher, W., U. Ziemann, J. Wissel, N. Dang, M. Kofler, S. Facchini, B. Boroojerdi, W. Poewe, and M. Hallett. 2002. Early consolidation in human primary motor cortex. Nature 415 (6872):640-4.

Nauczyciel, C., P. Hellier, X. Morandi, S. Blestel, D. Drapier, J. C. Ferre, C. Barillot, and B. Millet. 2010. Assessment of standard coil positioning in transcranial magnetic stimulation in depression. Psychiatry research.

O'Reardon, J. P., H. B. Solvason, P. G. Janicak, S. Sampson, K. E. Isenberg, Z. Nahas, W. M. McDonald, D. Avery, P. B. Fitzgerald, C. Loo, M. A. Demitrack, M. S. George, and H. A. Sackeim. 2007. Efficacy and safety of transcranial magnetic stimulation in the acute treatment of major depression: a multisite randomized controlled trial. Biological psychiatry 62 (11):1208-16.

Repeated Author. 2010. Reply regarding "efficacy and safety of transcranial magnetic stimulation in the acute treatment of major depression: a multisite randomized controlled trial". Biological psychiatry 67 (2):e15-7.

Paillere Martinot, M. L., A. Galinowski, D. Ringuenet, T. Gallarda, J. P. Lefaucheur, F. Bellivier, C. Picq, P. Bruguiere, J. F. Mangin, D. Riviere, J. C. Willer, B. Falissard, M. Leboyer, J. P. Olie, E. Artiges, and J. L. Martinot. 2010. Influence of prefrontal target region on the efficacy of repetitive transcranial magnetic stimulation in patients with medication-resistant depression: a [(18)F]-fluorodeoxyglucose PET and MRI study. The international journal of neuropsychopharmacology / official scientific journal of the Collegium Internationale Neuropsychopharmacologicum 13 (1):45-59.

Pascual-Leone, A., M. D. Catala, and A. Pascual-Leone Pascual. 1996. Lateralized effect of rapid-rate transcranial magnetic stimulation of the prefrontal cortex on mood. Neurology 46 (2):499-502.

Pascual-Leone, A., C. M. Houser, K. Reese, L. I. Shotland, J. Grafman, S. Sato, J. Valls-Sole, J. P. Brasil-Neto, E. M. Wassermann, L. G. Cohen, and et al. 1993. Safety of rapid-rate transcranial magnetic stimulation in normal volunteers. Electroencephalography and clinical neurophysiology 89 (2):120-30.

Paus, T., R. Jech, C. J. Thompson, R. Comeau, T. Peters, and A. C. Evans. 1997. Transcranial magnetic stimulation during positron emission tomography: a new method for studying connectivity of the human cerebral cortex. The Journal of neuroscience : the official journal of the Society for Neuroscience 17 (9):3178-84.

Riviere, D., J. F. Mangin, D. Papadopoulos-Orfanos, J. M. Martinez, V. Frouin, and J. Regis. 2002. Automatic recognition of cortical sulci of the human brain using a congregation of neural networks. Medical image analysis 6 (2):77-92. 
Rossini, P. M., M. D. Caramia, C. Iani, M. T. Desiato, G. Sciarretta, and G. Bernardi. 1995. Magnetic transcranial stimulation in healthy humans: influence on the behavior of upper limb motor units. Brain Res 676 (2):314-24.

Roth, Y., A. Zangen, and M. Hallett. 2002. A coil design for transcranial magnetic stimulation of deep brain regions. Journal of clinical neurophysiology: official publication of the American Electroencephalographic Society 19 (4):361-70.

Rothwell, J. C., M. Hallett, A. Berardelli, A. Eisen, P. Rossini, and W. Paulus. 1999. Magnetic stimulation: motor evoked potentials. The International Federation of Clinical Neurophysiology. Electroencephalogr Clin Neurophysiol Suppl 52:97-103.

Rusjan, P. M., M. S. Barr, F. Farzan, T. Arenovich, J. J. Maller, P. B. Fitzgerald, and Z. J. Daskalakis. 2010. Optimal transcranial magnetic stimulation coil placement for targeting the dorsolateral prefrontal cortex using novel magnetic resonance imageguided neuronavigation. Human brain mapping 31 (11):1643-52.

Shergill, S. S., M. J. Brammer, S. C. Williams, R. M. Murray, and P. K. McGuire. 2000. Mapping auditory hallucinations in schizophrenia using functional magnetic resonance imaging. Archives of general psychiatry 57 (11):1033-8.

Siebner, H. R., T. O. Bergmann, S. Bestmann, M. Massimini, H. Johansen-Berg, H. Mochizuki, D. E. Bohning, E. D. Boorman, S. Groppa, C. Miniussi, A. PascualLeone, R. Huber, P. C. J. Taylor, R. J. Ilmoniemi, L. De Gennaro, A. P. Strafella, S. Kahkonen, S. Kloppel, G. B. Frisoni, M. S. George, M. Hallett, S. A. Brandt, M. F. Rushworth, U. Ziemann, J. C. Rothwell, N. Ward, L. G. Cohen, J. Baudewig, T. Paus, Y. Ugawa, and P. M. Rossini. 2009. Consensus paper: Combining transcranial stimulation with neuroimaging (vol 2, pg 58, 2009). Brain Stimulation 2 (3):182-182.

Siebner, H. R., and J. Rothwell. 2003. Transcranial magnetic stimulation: new insights into representational cortical plasticity. Experimental brain research. Experimentelle Hirnforschung. Experimentation cerebrale 148 (1):1-16.

Siebner, H. R., G. Hartwigsen, T. Kassuba, J. C. Rothwell. 2009. How does transcranial magnetic stimulation modify neuronal activity in the brain? Implications for studies of cognition. Cortex. 45, (9):1035-1042.

Snyman, J. A. 2005. Practical Mathematical Optimization: An Introduction to Basic Optimization Theory and Classical and New Gradient-Based Algorithms. Springer Publishing.

Sparing, R., F. M. Mottaghy, M. Hungs, M. Brugmann, H. Foltys, W. Huber, and R. Topper. 2001. Repetitive transcranial magnetic stimulation effects on language function depend on the stimulation parameters. J Clin Neurophysiol 18 (4):326-30.

Thiel, A., B. Habedank, K. Herholz, J. Kessler, L. Winhuisen, W. F. Haupt, and W. D. Heiss. 2006. From the left to the right: How the brain compensates progressive loss of language function. Brain Lang 98 (1):57-65.

Thielscher, A., and T. Kammer. 2004. Electric field properties of two commercial figure-8 coils in TMS: calculation of focality and efficiency. Clin Neurophysiol 115 (7):1697708.

Walsh, V., and M. Rushworth. 1999. A primer of magnetic stimulation as a tool for neuropsychology. Neuropsychologia 37 (2):125-35.

Weiduschat, N., B. Habedank, B. Lampe, J. Poggenborg, A. Schuster, W. F. Haupt, W. D. Heiss, and A. Thiel. 2009. Localizing Broca's area for transcranial magnetic stimulation: Comparison of surface distance measurements and stereotaxic positioning. Brain stimulation 2 (2):93-102.

Wernicke, C., 1874. Der Aphasische Symptomenkomplex. Cohn and Weigert, Breslau. 


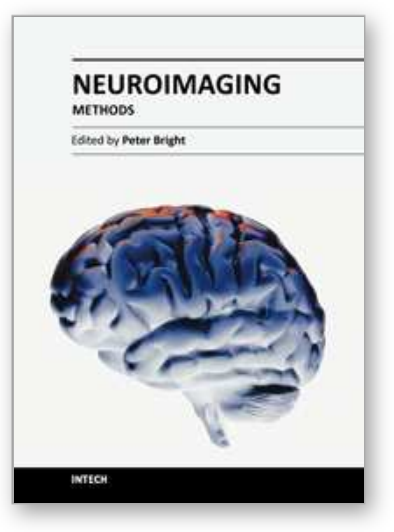

\author{
Neuroimaging - Methods \\ Edited by Prof. Peter Bright
}

ISBN 978-953-51-0097-3

Hard cover, 358 pages

Publisher InTech

Published online 17, February, 2012

Published in print edition February, 2012

Neuroimaging methodologies continue to develop at a remarkable rate, providing ever more sophisticated techniques for investigating brain structure and function. The scope of this book is not to provide a comprehensive overview of methods and applications but to provide a 'snapshot' of current approaches using well established and newly emerging techniques. Taken together, these chapters provide a broad sense of how the limits of what is achievable with neuroimaging methods are being stretched.

\title{
How to reference
}

In order to correctly reference this scholarly work, feel free to copy and paste the following:

Jamila Andoh and Jean-Luc Martinot (2012). A Triangulation-Based MRI-Guided Method for TMS Coil Positioning, Neuroimaging - Methods, Prof. Peter Bright (Ed.), ISBN: 978-953-51-0097-3, InTech, Available from: http://www.intechopen.com/books/neuroimaging-methods/a-triangulation-based-mri-guided-method-fortms-coil-positioning

\section{INTECH}

open science | open minds

\author{
InTech Europe \\ University Campus STeP Ri \\ Slavka Krautzeka 83/A \\ 51000 Rijeka, Croatia \\ Phone: +385 (51) 770447 \\ Fax: +385 (51) 686166 \\ www.intechopen.com
}

\author{
InTech China \\ Unit 405, Office Block, Hotel Equatorial Shanghai \\ No.65, Yan An Road (West), Shanghai, 200040, China \\ 中国上海市延安西路65号上海国际贵都大饭店办公楼 405 单元 \\ Phone: +86-21-62489820 \\ Fax: $+86-21-62489821$
}


(C) 2012 The Author(s). Licensee IntechOpen. This is an open access article distributed under the terms of the Creative Commons Attribution 3.0 License, which permits unrestricted use, distribution, and reproduction in any medium, provided the original work is properly cited. 